\title{
EXTERNAL CERVICAL ROOT RESORPTION INVOLVING MULTIPLE MAXILLARY TEETH IN A PATIENT WITH HEREDITARY HEMORRHAGIC TELANGIECTASIA
}

Paul C. Edwards ${ }^{1}$ M.Sc., D.D.S. and Tim McVaney ${ }^{2}$ D.D.S., M.S.

\author{
${ }^{1}$ Assistant Professor of Oral and Maxillofacial Pathology, Department of General \\ Dentistry, Creighton University School of Dentistry, Omaha, NE, and \\ ${ }^{2}$ Assistant Professor of Periodontics and Oral and Maxillofacial Surgery, \\ Department of Oral Surgery, Creighton University School of Dentistry, Omaha, \\ NE.
}

Keywords: hereditary hemorrhagic telangiectasia; HHT; external root resorption.

Address reprint requests to:

Dr. Paul C.Edwards D.D.S., M.S

Assistant Professor, Department of General Dentistry

Director, Surgical Oral Pathology Service

Creighton University School of Dentistry, 2500 California Plaza, Omaha, NE 68178

Tel: (402)-280-5025, Fax: (402)-280-5094

E-mail: pedwards@creighton.edu

Author's accepted manuscript; final version published as:

Edwards PC, McVaney T. External cervical root resorption involving multiple maxillary teeth in a patient with hereditary hemorrhagic telangiectasia. Oral Surg Oral Med Oral Pathol Oral Radiol Endod. 2005 Nov;100(5):585-91. 


\section{ABSTRACT}

Hereditary hemorrhagic telangiectasia $(\mathrm{HHT})$ is an inherited syndrome characterized by mucocutaneous telangiectases that commonly involve the tongue, lips, fingers and conjunctivae. While root resorption has been reported in association with central hemangiomas of bone, the association of HHT with external cervical root resorption has not been described to date.

We report a case of a 57 year old female with HTT who presented with advanced cervical root resorption involving multiple maxillary anterior teeth. Histologic examination of the gingival tissue adjacent to the area of root resorption demonstrated multiple thin-walled vascular elements as well as larger vascular channels surrounded by a thickened muscular layer. We hypothesize that the external root resorption seen in this case is the result of the HHT-related vascular process in the adjacent gingival tissue.

\section{INTRODUCTION}

Hereditary hemorrhagic telangiectasia (HHT; Osler-Weber-Rendu syndrome) is an autosomal dominantly inherited condition characterized by multiple mucocutaneous vascular malformations and visceral arteriovenous malformations ${ }^{1}$. The mucocutaneous telangiectases commonly present as scattered red papules, $1-2 \mathrm{~mm}$ in diameter, that are noted on the nasal and oropharyngeal mucosa. These represent superficial telangiectases; or dilatations of post-capillary venules and/or markedly dilated venules. These superficially 
located telangiectases are prone to bleeding after minimal trauma. Consequently, recurrent episodes of epistaxis are a common presenting complaint, with an average age of onset of approximately 12 years of age. The oral lesions, most frequently noted on the tongue, lip vermilion and buccal mucosa, are the most readily recognizable component of this syndrome. Additional telangiectases are often present on the skin of the hands and feet.

Large gastrointestinal tract arteriovenous malformations (AVMs), consisting of direct connections between arteries and veins that lack intervening capillaries, can result in chronic anemia and gastrointestinal hemorrhage, and are seen primarily in patients over age $50^{2}$.

Additional features of clinical significance include the development of arteriovenous malformations of the lung, liver and brain. AVM-induced pulmonary shunts can cause transient ischemic attacks, strokes, cyanosis and clubbing of the nails as well as predisposing to the development of cerebral abscesses. As a result, antibiotic prophylaxis, using the protocol suggested by the American Heart Association for the prevention of bacterial endocarditis, is recommended prior to surgical intervention for patients with suspected $\mathrm{HHT}$ until the presence of pulmonary AVMs can be ruled out ${ }^{3}$. Because the frequency and size of pulmonary AVMs appear to increase with advancing age, high risk patients without pulmonary AVMs should be rescreened periodically. Pregnant women with pulmonary AVMs are at a high risk for developing lung hemorrhage. 
The estimated prevalence of $\mathrm{HHT}$ is $2-20$ per 100,000 population ${ }^{1}$. There is some evidence of increased prevalence in patients of Anglo-Germanic, Latin, Scandinavian and Jewish ancestry.

Two separate subsets of HHT, HHT1 and HHT2, have been identified ${ }^{1}$. HHT1 is due to a mutation of the endoglin gene, which codes for a TGF-beta binding protein expressed in endothelial cells and involved in maintaining blood vessel integrity. HHT2 is caused by a mutation of the ALK-1 gene (activin receptor-like kinase-1), a type 1 serine-threonine kinase receptor, also expressed in high levels in endothelial cells. Patients with HHT2 have milder disease of late onset $^{4}$. Patients with an endoglin mutation $(\mathrm{HHT} 1)$ tend to present with an earlier onset of epistaxis and telangiectases. These patients are also significantly more likely to have pulmonary and cerebral arteriovenous malformations. However, the full spectrum of telangiectases and AVMs can also be seen in patients with an ALK-1 defect (HHT2).

Currently, clinical genetic screening for $\mathrm{HHT} 1$ and $\mathrm{HHT} 2$ is available in a number of laboratories (for an updated list see www.geneclinics.org). Prenatal testing is also available, but is not widely employed.

A clinical diagnosis can be reached in the presence of 3 of 4 major criteria $^{5}$ : recurrent episodes of epistaxis, multiple telangiectases, visceral lesions, and a family history of similarly affected relatives. Patients with only 2 major criteria should be reported as "suspected HHT" and followed closely due to the increased expression of disease traits with advancing age. 
Patients with recurrent epistaxis in the absence of telangiectases should be investigated to rule out the possibility of an undiagnosed bleeding diathesis. Isolated telangiectases are relatively common in otherwise healthy individuals, and can also be seen in the setting of chronic liver disease and pregnancy. The differential diagnosis of a patient with multiple skin and mucosal telangiectases would also include ataxia-telangiectasia, hereditary benign telangiectasia and CREST syndrome ${ }^{6}$ (calcinosis, Raynaud's phenomenon, esophageal dysfunction, sclerodactyly, and telangiectases). The appearance and distribution of the telangiectases is quite similar among these conditions.

In addition to oculocutaneous telangiectases, ataxia-telangiectasia is characterized by early onset progressive gait ataxia, progressively slurred speech, oculomotor apraxia, choreoathetosis, frequent infections, and a substantially increased risk of developing hematopoietic malignancies ${ }^{7}$.

Hereditary benign telangiectasia (generalized essential telangiectasia) is a rare benign inherited disorder characterized by widespread cutaneous telangiectases ${ }^{8}$. In contrast to $\mathrm{HHT}$, bleeding is uncommon and mucosal involvement is usually not seen.

Suspected cases of CREST syndrome can be confirmed by laboratory evaluation for the presence of anticentromere autoantibodies. Moreover, histologic examination reportedly can allow for differentiation between HHT and CREST syndrome ${ }^{9}$. In HHT, arterioles and venules communicate directly with each other in the absence of a capillary network. The dilated venules in HHT are reportedly surrounded by a thickened muscular layer ${ }^{10}$. In contrast, 
telangiectases in CREST syndrome show no muscular thickening. In addition, the presence of visceral involvement is most consistent with a diagnosis of HHT.

The dental practitioner should include $\mathrm{HHT}$ in the differential diagnosis when faced with a patient with multiple mucocutaneous telangiectases. Additionally, the dental practitioner may be faced with a patient with HHT who presents with prolonged gingival hemorrhage ${ }^{11}$. Until the presence of pulmonary AVMs can be ruled out, antibiotic prophylaxis should be prescribed prior to providing surgical dental treatment to patients with suspected HHT. Russi et al ${ }^{12}$ described a patient with multiple gingival telangiectases and periodontal abscesses who developed repeated episodes of septic pulmonary emboli. These emboli resolved only after correction of the patient's periodontal condition, suggesting a relationship to the presence of these gingival telangiectases.

From a dental perspective, only a limited number of articles dealing with HHT have been published in the English language dental literature in the past 10 years $^{11,13,14}$. Rhodus and Kuba ${ }^{15}$ described a patient with HHT who also presented with florid osseous dysplasia. To date, no specific dental findings attributed to HHT have been reported.

We report the first published case of a patient with HHT who presented with advanced external cervical root resorption involving multiple teeth.

\section{CASE REPORT}

A 57 year-old female patient was referred for examination and treatment following the discovery of extensive external cervical root resorption on the 
palatal aspect of her maxillary incisors. Her medical history was significant for hypertension and $\mathrm{HHT}$, initially diagnosed in her early forties following repeated episodes of epistaxis. The most severe episode, in 1978, resulted in significant hemorrhage and necessitated a blood transfusion. The patient required electrosurgical ablation of her nasal mucosa on 3 separate occasions. Pulmonary radiographs failed to identify any AVMs, although 2 small pulmonary nodules were noted. Several small AVMs were identified by colonoscopy, but treatment was not deemed to be necessary.

The patient reported that her father had died in his early thirties secondary to an "infection". The patient had one brother, who died at age 28 from a "cerebral infection", and four children, three of whom have since been diagnosed with HHT. Neither the patient nor affected family members have undergone gene testing, so it is not known if she has HHT1 or HHT2. The patient also reported 2 previous episodes of atrial fibrillation that required electroconversion. Medications taken included lisinopril and sotalol.

Clinical examination revealed a number of telangiectases, involving primarily the hard palate (Figure 1) and lips. Panoramic radiographic evaluation revealed a normal complement of teeth (absent the third molars) with evidence of generalized chronic moderate periodontitis. The right maxillary canine, lateral incisor and central incisor and the left maxillary canine demonstrated extensive external cervical root resorption (Figure 2). Periodontal assessment revealed 5-7 $\mathrm{mm}$ pocketing and moderate bleeding on probing. The patient denied any history 
of bruxism, trauma or tooth bleaching. A lateral cephalometric radiograph did not identify any lesions suggestive of a central vascular process.

Crown lengthening surgery was required to obtain adequate access prior to restoration of the areas of external root resorption. This excised tissue, which was removed from the area of the resorptive defects along the palatal root surfaces of the teeth, was submitted for examination. Histopathologic examination of this tissue (Figures 3a, 3b) demonstrated the presence of multiple thin-walled vascular elements immediately below the surface epithelium. Located deeper in the submucosa were numerous large, dilated vascular elements surrounded by thickened muscular layers. Inflammation was minimal, consisting primarily of scattered lymphocytes, plasma cells and occasional mast cells.

Due to the severity of the external cervical root resorption, the affected teeth required endodontic treatment. Completion of the endodontic therapy was accomplished with some difficulty due to the continuous overgrowth of the previously resected gingival tissue into the resorptive root defects. The right maxillary lateral incisor presented with significant loss of coronal structure, which fractured after the completion of the endodontic therapy. This tooth was maintained as a partial overdenture abutment. Rapid external resorption of the right maxillary canine occurred during the endodontic phase (Figures 4a, 4b). Post-treatment clinical and radiographic examination showed good healing.

In the 18 month period following the endodontic intervention, the patient experienced several episodes of spontaneous gingival bleeding involving the 
maxillary anterior palatal gingiva that were controlled with laser coagulation/cautery (Lasersmile, Biolase Technology, San Clemente, California).

\section{DISCUSSION}

Root resorption can be classified based on the primary site of resorption as internal root resorption or external root resorption. The latter can be further subclassified as external cervical root resorption or external apical root resorption. Internal root resorption is generally related to pulpal inflammation and/or pathosis. While many cases of external tooth resorption are idiopathic, common identifiable causes include trauma, chronic periodontal inflammation, internal bleaching and pressure from orthodontic tooth movement ${ }^{16}$. External root resorption also occurs secondary to pressure from slow growing cysts, tumors and fibro-osseous lesions. Rare cases have been reported in patients with Goltz syndrome (focal dermal hypoplasia syndrome) ${ }^{17}$, Ehlers-Danlos syndrome ${ }^{18}$ and oxalosis $^{19}$.

In most cases, external cervical root resorption is not believed to be related to pulpal pathology ${ }^{20}$, but appears to be the result of injury to the cervical attachment apparatus. The exact mechanism of tooth resorption is poorly understood, but is believed to involve the action of osteoclast-like cells ("dentinoclasts") originating from hematopoietic stem cells in the bone marrow. It has been suggested ${ }^{21}$ that the presence of inflamed fibrovascular connective tissue adjacent to root surface lacking an intact periodontal ligament is a prerequisite for cervical root resorption. 
Much of the research on root resorption has centered on identifying the factors involved in promoting external apical root resorption in cases associated with orthodontic treatment or periodontal inflammation. Genetic factors, in part mediated through polymorphisms in the gene for interleukin 1-beta, may predispose certain patients to an increased risk of orthodontically-induced tooth resorption $^{22}$.The inflammatory cytokines interleukin-1 and tumor necrosis factor alpha appear to be involved in the initiation and progression of external root resorption ${ }^{23}$. These cytokines are upregulated in response to periodontal inflammation, periapical pathology and mechanical stress. Additional cytokines are also synthesized by periodontal ligament fibroblasts following mechanical stress $^{24}$. Both interleukin-1, produced by a number of cell types including macrophages, fibroblasts, and lymphocytes, and tumor necrosis factor alpha, synthesized by activated monocytes and macrophages, are strong mediators of osteoclastic bone resorption.

The association between central vascular anomalies of bone and external root resorption has been well documented in the dental literature. Noreau and colleagues $^{25}$ reported a case of a 9-year-old girl with resorption of the roots of a permanent molar in the area of a high-flow vascular malformation of the mandible. In a review of 20 published cases of osseous hemangiomas of the maxillofacial region, Fernandez and colleagues ${ }^{26}$ noted 5 cases of root resorption associated with osseous hemangiomas ( $25 \%$ of cases). Specifically, they noted that root resorption was significantly more common in cases in which the 
vascular lesion was located in close proximity to the apical region of teeth. None of these cases were noted in patients with an underlying diagnosis of HHT.

Osseous involvement, though quite rare in $\mathrm{HHT}$, has been reported ${ }^{27,28,29,30}$ and ranges from classic vertebral hemangiomas to calvarial angiomatosis. We were unable to demonstrate any intrabony vascular process in our patient.

To date, there have been no published reports of root resorption associated with $\mathrm{HHT}$. In our patient with $\mathrm{HHT}$ we were able to histologically demonstrate that gingival tissue removed from resorptive root defects contained multiple thin-walled vascular elements as well as numerous large, dilated muscular vessels. This presentation of dilated venules surrounded by a thickened muscular layer is characteristic of $\mathrm{HHT}^{10}$. These findings would suggest a direct relationship between $\mathrm{HHT}$ and the root resorption observed in this patient. Supporting this view are isolated reports of external root resorption occuring in patients with reactive gingival lesions, including pyogenic granulomas $^{31}$ and peripheral giant cell granulomas ${ }^{32,33}$. All of these lesions are characterized histologically by a prominent vascularity. The exact mechanism by which a vascular anomaly or vascular proliferation leads to root resorption is unknown.

The possibility of a coincidental association between the external root resorption and the presence of multiple vascular telangiectases in the neighboring gingival tissue cannot be entirely ruled out. Moreover, we are unable to evaluate what contribution, if any, the presence of chronic periodontal disease 
may have played in the extensive resorption seen in this case. However, the presence of multiple dilated venules intimately associated with the resorptive process as well as previously demonstrated associations between external root resorption and both central vascular anomalies and peripheral reactive vascular processes, would argue strongly in favor of a direct causal relationship.

\section{CONCLUSIONS}

This is the first reported case of external cervical root resorption involving a number of maxillary anterior teeth in a patient with $\mathrm{HTT}$, which, we hypothesize, is most probably related to the presence of multiple vascular telangiectases of the overlying gingiva. 
Figure 1: Clinical photograph of patient with HHT demonstrating numerous telangiectases involving the hard palate.

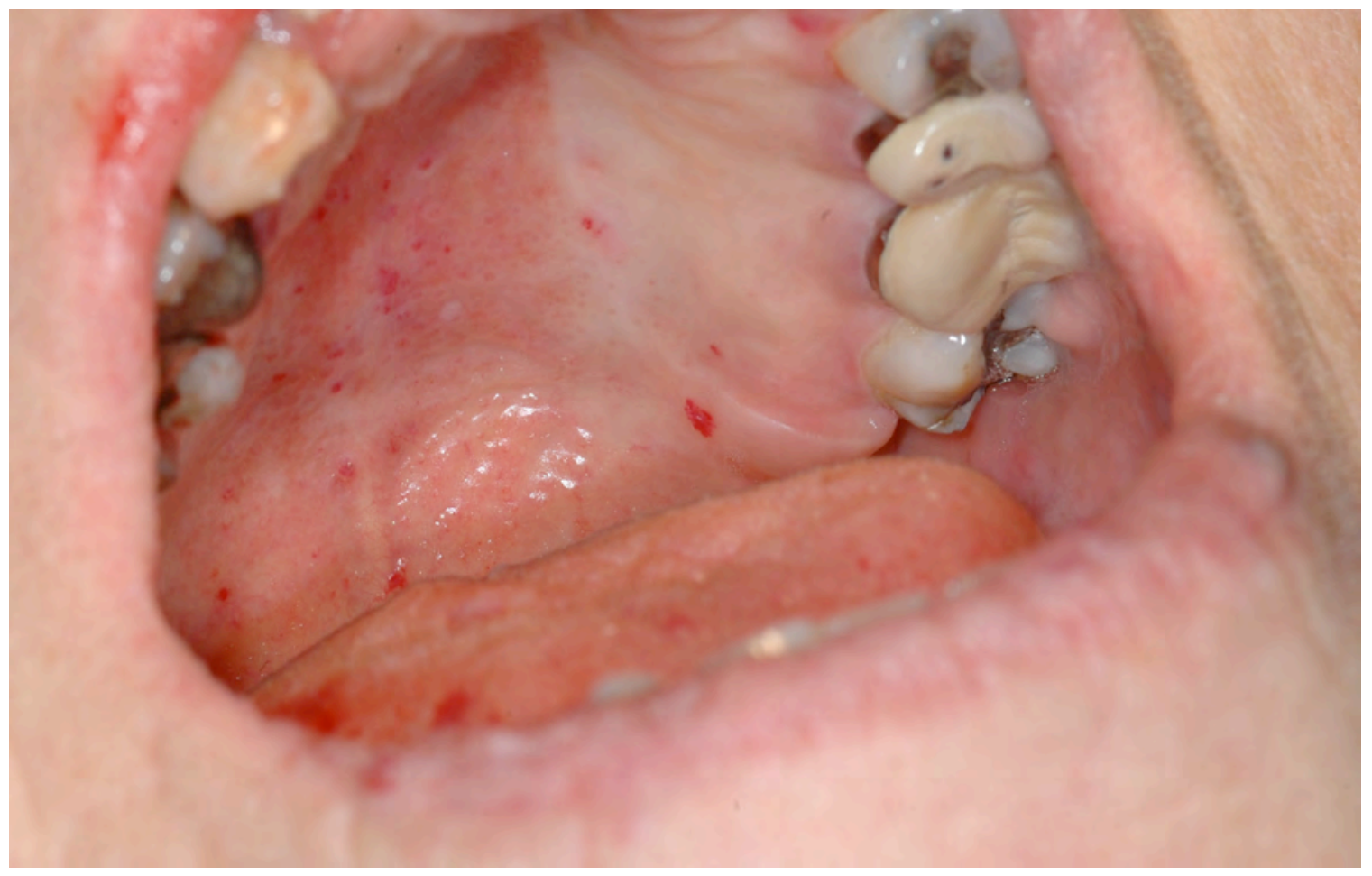


Figure 2: Periapical radiographs of anterior maxillary dentition showing external resorption of the right maxillary canine, lateral incisor and central incisor and the left maxillary canine. Radiographs were taken after crown lengthening surgery but prior to endodontic therapy.

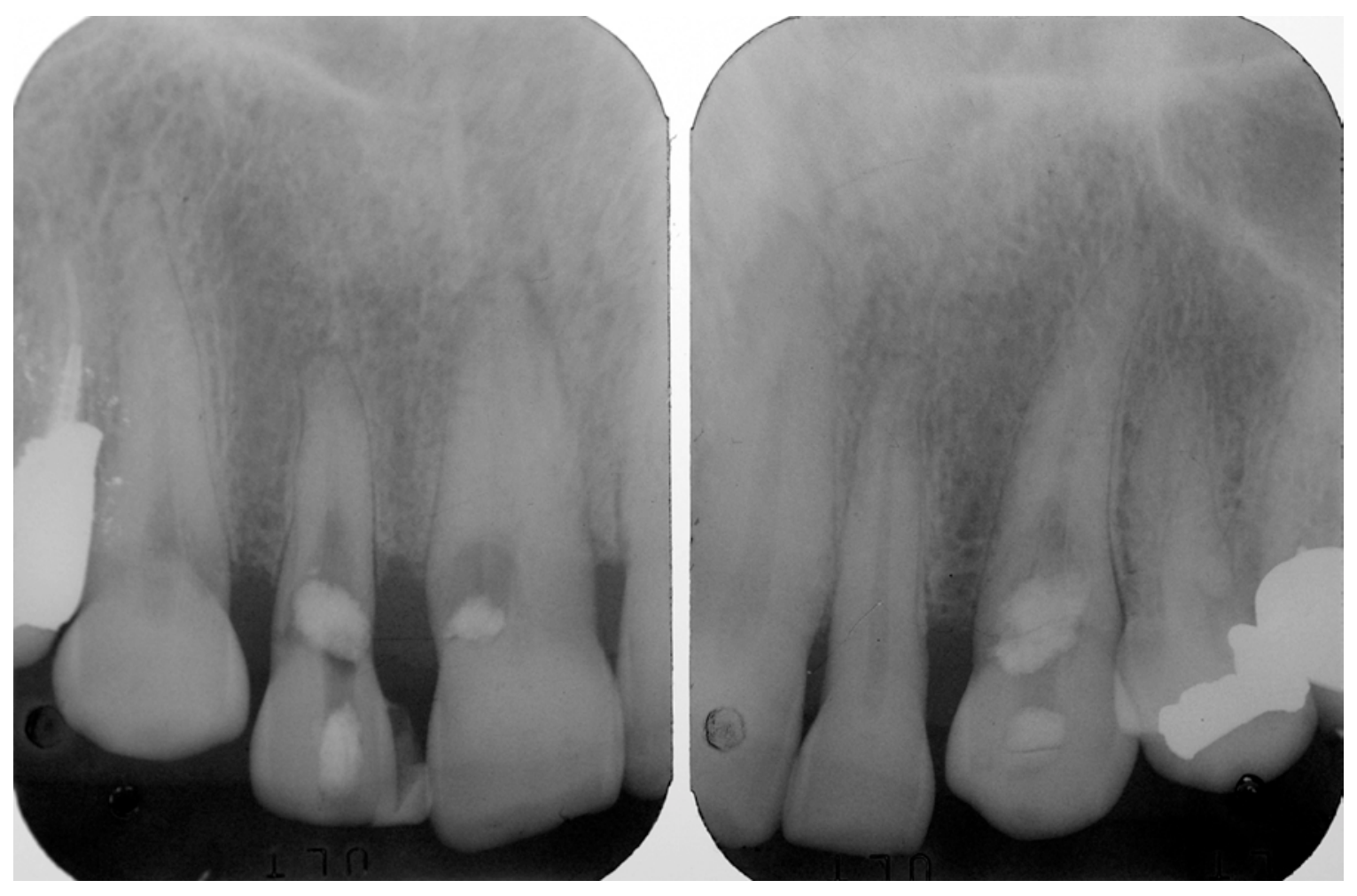


Figure 3: Photomicrograph of biopsy specimen harvested from the area of the resorptive defects along the palatal root surfaces adjacent to the right maxillary canine, lateral incisor and central incisor and the left maxillary canine root defects. Located immediately below the surface epithelium are multiple thinwalled vascular elements. Numerous large, dilated vessels surrounded by a thickened muscular layer are seen deeper in the submucosa. Hematoxylin and eosin stain. Original magnification 40x.

A. Higher magnification view of large muscular vessels. Hematoxylin and eosin stain. Original magnification 100x.

B. Higher magnification view of large muscular vessels. Anti-CD31 immunoperoxidase staining. Original magnification 100x. 


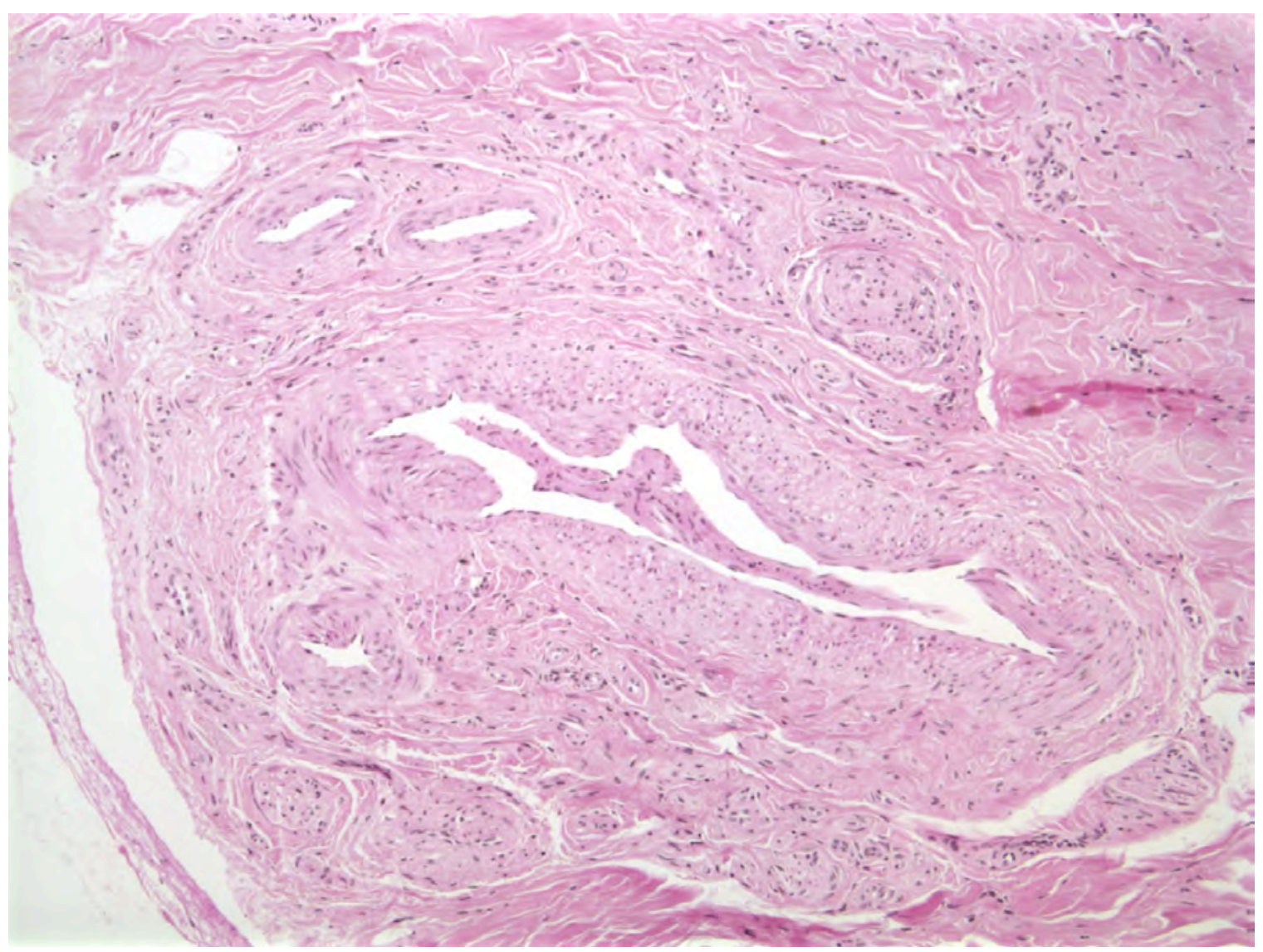




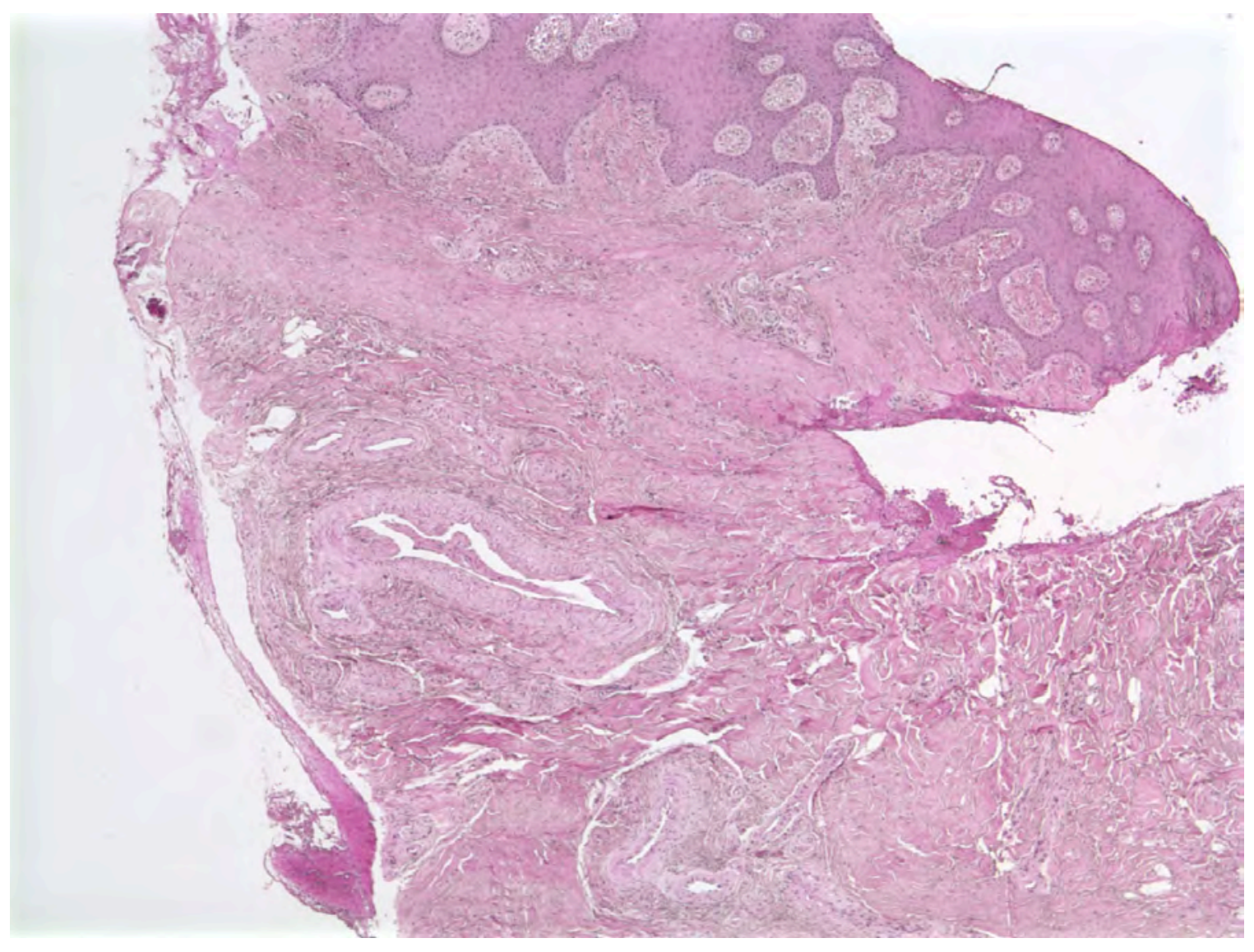


Figure 4:

A: Endodontic treatment on the right maxillary lateral incisor and central incisor and the left maxillary canine is completed. Endodontic treatment has not yet been performed on the right maxillary canine. In the interval between the start of endodontic treatment (Figure 2) and the taking of this radiograph, the right maxillary canine experienced significant external root resorption. Note that the radiopaque outline of the canal can still be visualized through the external resorptive defect.

B: Periapical radiograph of the right anterior maxillary teeth taken at the completion of endodontic therapy on the right maxillary canine.

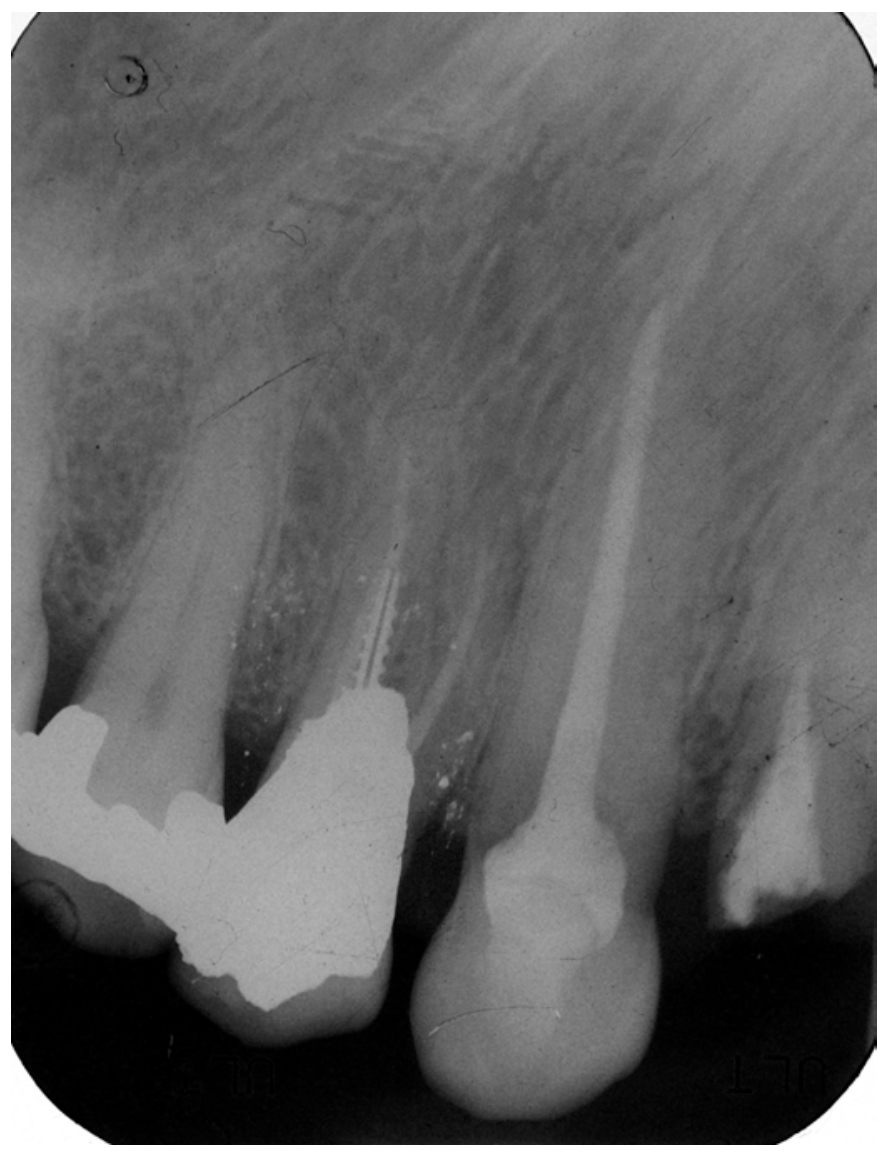




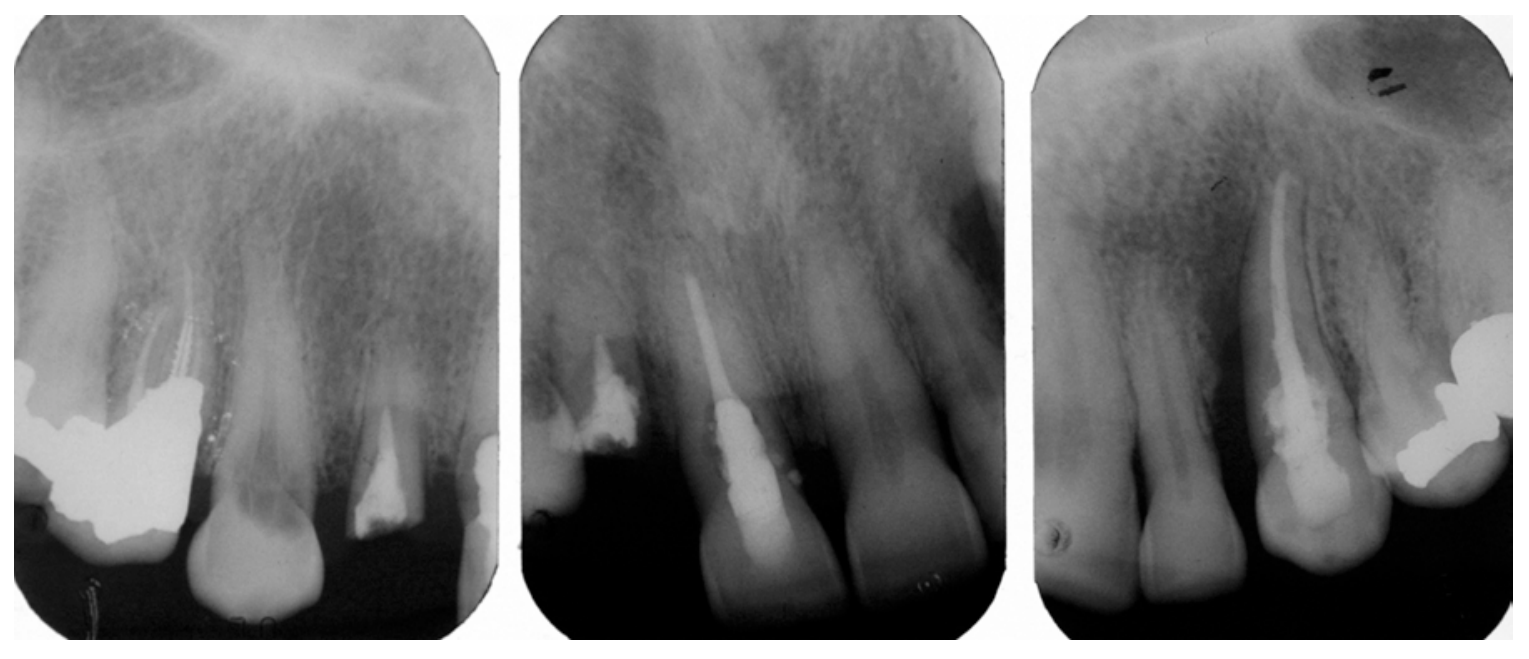




\section{REFERENCES}

${ }^{1}$ Begbie ME, Wallace GM, Shovlin CL. Hereditary haemorrhagic telangiectasia (Osler-Weber-Rendu syndrome): a view from the $21^{\text {st }}$ century. Postgrad Med $\mathrm{J}$ 2003;79:18-24.

${ }^{2}$ Abdalla SA, Geisthoff UW, Bonneau D, Plauchu H, McDonald J, Kennedy S, et al. Visceral manifestations in hereditary haemorrhagic telangiectasia type $2 . \mathrm{J}$ Med Genet 2003;40:494-502.

${ }^{3}$ Mohler ER, Monahan B, Canty MD, Flockhart DA. Cerebral abscess associated with dental procedure in hereditary haemorrhagic telangiectasia. Lancet 1991;338:508-9.

${ }^{4}$ Berg J, Porteous M, Reinhardt D, Gallione C, Holloway S, Umasunthar T, et al. Hereditary haemorrhagic telangiectasia: a questionnaire based study to delineate the different phenotypes caused by endoglin and ALK1 mutations. J Med Genet 2003;40:585-90.

${ }^{5}$ Shovlin CL, Guttmacher AE, Buscarini E, Faughnan ME, Hyland RH, Westermann CJ, et al. Diagnostic criteria for hereditary hemorrhagic telangiectasia (Rendu-Osler-Weber syndrome). Am J Med Genet 2000;91:66-7. ${ }^{6}$ Lee JB, Ben-Aviv D, Covello SP. The diagnostic quandary of hereditary haemorrhagic telangiectasia vs. CREST syndrome. Br-J-Dermatol 2001;145:6469.

${ }^{7}$ Taylor, AM. Chromosome instability syndromes. Best Pract Res Clin Haematol 2001;14:631-44. 
${ }^{8}$ Brancati F, Valente EM, Tadini G, Caputo V, DiBenedetto A, Gelmetti C, et al. Autosomal dominant hereditary benign telangiectasia maps to the $\mathrm{CMC} 1$ locus for capillary malformation on chromosome 5q14. J Med Genet 2003;40:849-53. ${ }^{9}$ Braverman IM, Keh A, Jackobson BS. Ultrastructure and three-dimensional organization of the telangiectases of hereditary hemorrhagic telangiectasia. $\mathrm{J}$ Invest Dermatol 1990;95:422-7.

${ }^{10}$ Marchuk DA, Srinivasan S, Squire TL, Zawistowski JS. Vascular morphogenesis: tales of two syndromes. Human Mol Genet 2003;12, Review Issue 1:R97-R112.

${ }^{11}$ Finkbeiner RL. Progressive laser treatment of hereditary hemorrhagic telangiectasia of the gingival: case report. Int J Perio Restor Dent 2004;24:28894.

${ }^{12}$ Russi EW, Dazzi H, Gaumann N. Septic pulmonary embolism due to periodontal disease in a patient with hereditary hemorrhagic telangiectasia. Respiration 1996;63:117-9.

${ }^{13}$ Christensen GJ. Nosebleeds may mean something much more serious: an introduction to HHT. J Am Dent Assoc 1998;129:635-7.

${ }^{14}$ Flint SR, Keith O, Scully C. Hereditary hemorrhagic telangiectasia: family study and review. Oral Surg Oral Med Oral Pathol 1988;66:440-4.

${ }^{15}$ Rhodus NL, Kuba R. Hereditary hemorrhagic telangiectasia with florid osseous dysplasia. Report of a case with differential diagnostic considerations. Oral Path Oral Med Oral Pathol 1993;75:48-53. 
${ }^{16}$ Gunraj MN. Dental root resorption. Oral Surg Oral Med Oral Pathol Oral Radiol Endod 1999;88:647-53.

${ }^{17}$ Baxter AM, Shaw MJ, Warren K. Dental and oral lesions in two patients with focal dermal hypoplasia (Goltz syndrome). Br Dent J 2000;189:550-3.

${ }^{18}$ Karrer S, Landthaler M, Schmaltz G. Ehlers-Danlos type VIII: review of the literature. Clin Oral Invest 2000;4:66-9.

${ }^{19}$ Moskow BS. Periodontal manifestations of hyperoxaluria and oxalosis. J Periodontol 1989;60:271-8.

${ }^{20}$ Bergmans L, Van Cleynenbreugel J, Verbeken E, Wevers M, Van Meerbeek B, Lambrechts P. Cervical external root resorption in vital teeth: X-ray microfocus, tomographical and histopathological case study. J Clin Perio 2002;29:80-5. ${ }^{21}$ Gold SI, Hasselgren S. Peripheral inflammatory root resorption. A review of the literature with case reports. J Clin Perio 1992;19:523-34.

22 Hartsfield JK Jr, Everett ET, Al-Qawasmi RA. Genetic factors in external apical root resorption and orthodontic treatment. Crit Rev Oral Biol Med 2004;15:115-22.

${ }^{23}$ Zhang D, Goetz W, Braumann B, Bourauel C, Jaeger A. Effect of soluble receptors to interleukin-1 and tumor necrosis factor alpha on experimentally induced root resorption in rats. J Periodontal Res 2003;38:324-32.

${ }^{24}$ Kimoto S, Matsuzawa M, Matsubara S, Komatsu T, Uchimura N, Kawase T, et al. Cytokine secretion of periodontal ligament fibroblasts derived from human deciduous teeth: effect of mechanical stress on the secretion of transforming 
growth factor-beta 1 and macrophage colony stimulating factor. J Periodontal Res 1999;34:235-43.

${ }^{25}$ Noreau G, Landry PE, Morais D. Arteriovenous malformation of the mandible: review of literature and case history. J Can Dent Assoc 2001;67:646-51.

${ }^{26}$ Fernandez LR, Luberti RF, Dominguez FV. Radiographic features of osseous hemangioma in the maxillo-facial region. Bibliographic review and case report. Med Oral 2003;8:166-77.

${ }^{27}$ Murphey MD, Fairbairn KJ, Parman LM, Baxter KG, Parsa MB, Smith WS. Musculoskeletal angiomatous lesions: radiologic-pathologic correlation. Radiographics 1995;15:893-917.

${ }^{28}$ Mirra JM, Arnold WD. Skeletal hemangiomatosis in association with hereditary hemorrhagic telangiectasia. J Bone Joint Surg Am 1973;55:850-4.

${ }^{29}$ Abdullah DC, Hallisey MJ, Muraki AS, Schellinger DR. Diffuse calvarial hemangiomatosis associated with hereditary hemorrhagic telangiectasia. Am J Neuroradiol1989;10:559-61.

${ }^{30}$ Czerniak P, Schoor S. Hereditary hemorrhagic telangiectasia with involvement of bone. Am JRadiol 1955;74:299-303.

${ }^{31}$ Goodman-Topper ED, Bimstein E. Pyogenic granuloma as a cause of bone loss in a twelve-year-old child: report of case. J Dent Child 1994;61:65-7.

${ }^{32}$ Nedir R, Lombardi T, Samson J. Recurrent peripheral giant cell granuloma associated with cervical resorption. J Periodontol 1997;68:381-4.

${ }^{33}$ Amler MH. Peripheral giant cell granuloma. NY State Dent J 1992;58:38-9. 